\title{
Esthiomene resulting from cutaneous tuberculosis of external genitalia
}

\author{
R P C NAIK, C R SRINIVAS, C BALACHANDRAN, P K NARAYAN, K RAMNARAYAN, AND \\ R C SAHOO \\ From the Kasturba Medical College and Hospital, Manipal, Karnataka, India
}

SUMMARY Tuberculosis of the external genitalia, which is rare, is usually secondary to pulmonary tuberculosis. Longstanding lupus vulgaris of the buttocks extending to the vulva and resulting in esthiomene is reported here. There was no evidence of tuberculosis of any other organ.

\section{Introduction}

Esthiomene, which is known to occur after lymphogranuloma venereum and granuloma inguinale, ${ }^{\prime}$ is not a common sequel of cutaneous tuberculosis. We report a case of lupus vulgaris of the buttocks and vulva resulting in esthiomene.

\section{Case report}

A woman aged 22 presented with multiple swellings of 15 years' duration on her buttocks and genitalia. The initial nodules on the right buttock gradually extended to form irregular plaques on both buttocks (fig 1) and the vulva. The edge of the lesion was hyperkeratotic. Induration of the vulva, which had been noticed about three years previously, gradually progressed to form

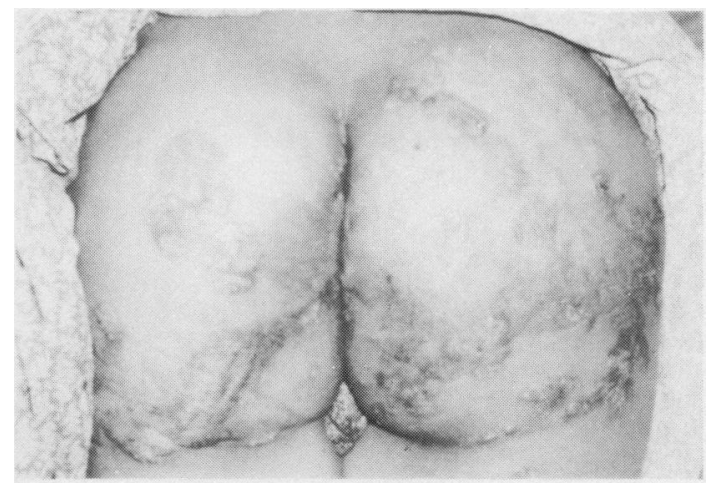

FIG 1 Lupus vulgaris of buttocks.

Address for reprints: Dr C R Srinivas, Department of Dermatology and STD, Kasturba Hospital, Manipal, 576 119, Karnataka, India Accepted for publication 9 September 1986. large polypoidal masses (fig 2). The inguinal lymph nodes were not noticeably enlarged. There was no history of fever, sexual abuse as a child, or extramarital sexual contact.

The haemaglobin concentration, white cell count and differential, erythrocyte sedimentation rate, and chest $x$ ray were normal. The Venereal Disease Research Laboratory (VDRL) test and Treponema pallidum haemagglutination assay (TPHA) gave negative results. Donovan bodies were not detected by repeated examination of tissue smears. Sections of biopsy specimens stained with haemotoxylin and eosin, showed tubercular granuloma. Antitubercular chemotherapy followed by partial vulvectomy six months later resulted in remission of the lupus vulgaris lesion, and gave a good cosmetic result.

\section{Discussion}

Genital tuberculosis constitutes $0 \cdot 2 \%$ to $2 \%$ of all gynaecological cases, and in 1 to $2 \%$ of these the

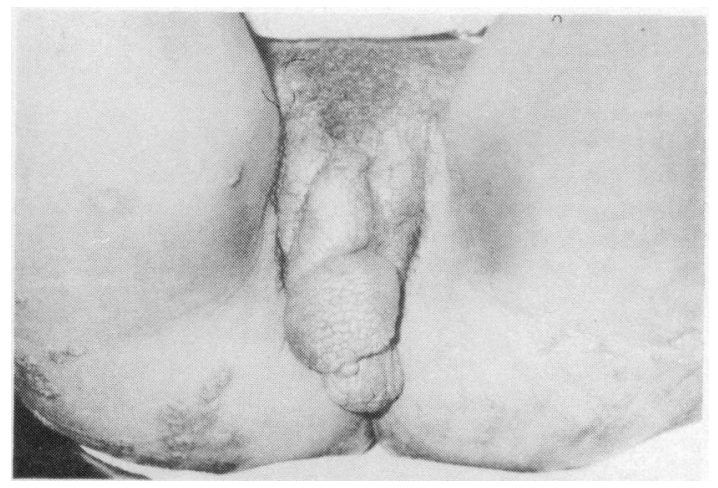

FIG 2 Esthiomene. 
external genitalia are affected. ${ }^{2}$ The lesions are ulcerative or hypertrophic in $10 \%$ of cases. ${ }^{2}$ Millar et al have reported a case of ulcerative vulval tuberculosis. ${ }^{3}$ In children the fingers of the attendants are a possible source of infection. ${ }^{2}$ Esthiomene, which is commonly associated with lymphogranuloma venereum and less commonly a complication of granuloma inguinale, ${ }^{1}$ is attributed by some to lymphatic stasis and by others to an active chronic inflammatory process. ${ }^{4}$ Damage to lymphatic vessels results in lymphatic obstruction and oedema. ${ }^{4}$ Esthiomene has not been reported previously as a sequel of cutaneous tuberculosis.

\section{References}

1. Sowmini CN. Granuloma inguinale. In: Holmes $\mathrm{KK}, \mathrm{Mårdh}$ $\mathrm{P}-\mathrm{A}$, eds. International perspective on neglected sexually transmitted diseases. Washington: Hemisphere Publishing Corporation, 1983:205-17.

2. Crossley J, Husain OAN. Tuberculosis of the vulva. $\mathrm{Br}$ Med J 1958;i:1286.

3. Millar JW, Holt S, Gilmour HM, Robertson DHH. Vulval tuberculosis. Tubercle 1979;60:173-6.

4. Osoba AS. Lymphogranuloma venereum. In: Holmes KK, Mårdh P-A, eds. International perspective on neglected sexually transmitted diseases. Washington: Hemisphere Publishing Corporation:'1983:193-204. 